Original Research Paper

\title{
Properties of ZnO:Ga Thin Films Deposited by de Magnetron Sputtering: Influence of Ga-Doped Concentrations on Structural and Optical Properties
}

\author{
${ }^{1}$ Putut Marwoto, ${ }^{2}$ Edy Wibowo, ${ }^{1}$ Dwi Suprayogi, \\ ${ }^{1}$ Sulhadi Sulhadi, ${ }^{3}$ Didik Aryanto and ${ }^{1}$ Sugianto Sugianto \\ ${ }^{1}$ Material Research Group, Department of Physics, Faculty of Mathematics and Natural Science, \\ Universitas Negeri Semarang (Unnes), Gunungpati Semarang 50229, Indonesia \\ ${ }^{2}$ Engineering Physics, School of Electrical Engineering, Telkom University, \\ Jalan Telekomunikasi No.1, Terusan Buah Batu, Bandung 40257, Indonesia \\ ${ }^{3}$ Physics Research Centre, Indonesia Academy of Science, Puspitek, Serpong 15314, Indonesia
}

Article history

Received: 06-04-2016

Revised: 26-11-2016

Accepted: 12-12-2016

Corresponding Author: Putut Marwoto

Material Research Group, Department of Physics, Faculty of Mathematics and Natural Science, Universitas Negeri Semarang, Semarang,

Indonesia

Email: pmarwoto@yahoo.com

\begin{abstract}
ZnO:Ga thin films were deposited on corning glass by dc magnetron sputtering. Influence of Ga-doped concentrations on the structural and optical properties of $\mathrm{ZnO}: \mathrm{Ga}$ thin films were investigated. The XRD patterns show that the crystallinity of deposited films improved with the increase of Ga concentrations from 1 to $2 \%$, then decrease at $3 \%$ Ga concentrations. The optical transmittance of films with $1 \%$ and $2 \%$ Ga concentration reach $85 \%$ in the visible range, while at $3 \% \mathrm{Ga}$ concentration the transmittance of film only $70 \%$. We observed that the band gap of film change due to the addition of Ga dopant. The band gap of the films are 3.27, 3.28 and $3.21 \mathrm{eV}$ for 1,2 and $3 \%$ Ga-doped concentrations, respectively.
\end{abstract}

Keywords: ZnO:Ga Thin Films, DC Magnetron Sputtering, Structural, Optical Properties

\section{Introduction}

Transparent conductive oxide (TCO) such as indium tin oxide (ITO) thin films has been widely used as transparent electrodes, window materials for display and solar cells (Kao et al., 2012). Many studies have been conducted in order to obtain an alternative material of ITO for TCO application. This is because although possess fascinating properties, the price of ITO is expensive. $\mathrm{ZnO}$ is a promising alternative material for ITO in the TCO applications due to possess some promising properties such as inexpensive, non-toxic, low deposition temperature and chemically stabile (Ma et al., 2007) as well as wide optical band-gap (3.4 eV) (Lee, 2013). Nevertheless, the transmittance and electrical conductivity of $\mathrm{ZnO}$ material is inferior to ITO. Besides, the properties of the pure $\mathrm{ZnO}$ are unstable (Yang et al., 2009). Therefore, further treatment for upgrading the properties of $\mathrm{ZnO}$ is required. The enhancement of properties could be done by precisely control the growth processes and use several appropriate dopants (Nayeef et al., 2013).

Shin et al. (2009) have deposited $\mathrm{ZnO}$ films by introducing $\mathrm{B}, \mathrm{Al}, \mathrm{Ga}$ and In dopants. They have reported that the atom of dopants replace the $\mathrm{Zn}$ site in the $\mathrm{ZnO}$ crystal so that one more free of electron was generated. From all dopant elements, $\mathrm{Ga}$ is the most effective for $\mathrm{ZnO}$ (Yang et al., 2009). Ga elements were selected due to the length of $\mathrm{Ga}-\mathrm{O}$ bond $(1.92 \AA)$ almost corresponds to $\mathrm{Zn}-\mathrm{O}$ bond $(1.97 \AA)$. As a result, the lattice mismatch with $\mathrm{ZnO}$ is very small. So the addition of $\mathrm{Ga}$ doping in the some extent is expected increase the transmittance and conductivity of films but does not damage the crystal structure of $\mathrm{ZnO}$ as host material. It because the crystal structure is damaged, the transmittance and the conductivity of films would decrease.

Numerous studies have reported the deposition of $\mathrm{ZnO}: \mathrm{Ga}$ films with variation deposition techniques such as atomic layer deposition (Maeng and Park, 2013), sol-gel method (Lin et al., 2010), chemical vapour deposition (Yang et al., 2009), physical vapour deposition (Lee, 2013), pulsed laser deposition (Shin et al., 2009), magnetron sputtering (Sheu et al., 2007), DC reactive magnetron sputtering (Ma et al., 2007) and RF sputtering (Yu et al., 2005). It has been reported that the properties of $\mathrm{ZnO}: \mathrm{Ga}$ thin films are dependent on the deposition methods.

Among this techniques sputtering method possess several advantages such as the films can be deposited in large area of substrate with relatively high of growth rate 
(Zhang et al., 2002). Besides, sputtering method is considered as a technique with cost-effective in the use of source materials (Ma et al., 2007). The source material in the pellet form can be used repeatedly, while the resulted films have high similarity in the quality (Marwoto et al., 2016).

The objective of this study is to investigate the influence of Ga-doped concentrations on the structural and optical properties $\mathrm{ZnO}: \mathrm{Ga}$ thin films grown by $\mathrm{dc}$ magnetron sputtering. The structural parameters of films such as the lattice constant, crystal size, $d$-spacing, lattice strain and lattice stress were determined based on XRD results, while the percentage of transmittance and the optical band-gap were determined based on UV-vis analysis. The growth parameters that used in this study is the optimum parameters of $\mathrm{ZnO}$ films deposition that had previously been conducted (Marwoto et al., 2014).

\section{Materials and Methods}

A homemade dc magnetron sputtering system (Marwoto et al., 2016) was used to growth $\mathrm{ZnO}$ :Ga thin films on corning glass at $400^{\circ} \mathrm{C}$ of substrate temperature. A sintered target with a mixture of $\mathrm{ZnO}(99.999 \%)$ and $\mathrm{Ga}_{2} \mathrm{O}_{3}(99.999 \%)$ was used as the source materials. The target diameter was $2.5 \mathrm{~cm}$ with total mass of $10 \mathrm{~g}$. The amount of $\mathrm{Ga}_{2} \mathrm{O}_{3}$ that added to the target was varied at concentration of 1,2 and 3 (wt.\%). The dc sputtering power and deposition time were kept constant at 30 watt and $1 \mathrm{~h}$, respectively. Corning glass substrates were cleaned using acetone and methanol solution for 15 minutes in the ultrasonic bath.

The crystallographic properties of the deposited films were analyzed using X-Ray Diffraction spectroscopy (XRD) with $\mathrm{Cu}-K_{\alpha}$ radiation (1.5406 $\AA$ ). The optical transmittance measurement was conducted by UV-Vis spectroscopy. All samples were characterized at room temperature.

\section{Results and Discussion}

Figure 1 shows the XRD spectrum of $\mathrm{ZnO}: \mathrm{Ga}$ thin films at three different Ga-doped concentration (wt\%). As shown in Fig. 1, a strong (002) peak and a weak (004) peak are observed for all samples. The crystalline dimension of $2 \theta$ along $c$-axis is $34.57,34.44$ and 34.05 for 1,2 and $3 \%$ Ga concentration, respectively. These peaks indicate that the crystal structure of films are independent to the Ga concentration. However, the film deposited with $3 \%$ Ga concentration showed a weak (101) peak. It indicated that all of the deposited films are polycrystalline with wurtzite structure and had a preferred orientation with $c$-axis that perpendicular to the substrates ( $\mathrm{Yu}$ et al., 2005). We found that $\mathrm{Ga}_{2} \mathrm{O}_{3}$ phase was not found on the XRD patterns of deposited films. It indicates that $\mathrm{Ga}$ atoms are likely substitute $\mathrm{Zn}$ atoms in the hexagonal lattice or segregate to the noncrystalline region to form $\mathrm{Ga}-\mathrm{O}$ bond. Ma et al. (2007) have reported that $\mathrm{Ga}$ atoms are able to ionize into $\mathrm{Ga}^{3+}$ then substitute $\mathrm{Zn}^{2+}$ and generate a free electron from each $\mathrm{Ga}$ atoms.

These XRD patterns also showed that the increase of $\mathrm{Ga}$ content is change the diffractions intensity. As the concentration of Ga doped increases from $1 \%$ to $2 \%$, the (002) peak intensity is increased. When the concentration of $\mathrm{Ga}$ is increased to $3 \%$, the intensity of the (002) peak is decreased, but the (001) peak is observed. The $(001)$ peak was not observed on the $\mathrm{ZnO}: \mathrm{Ga}$ film with $1 \%$ and $2 \%$ consentration of $\mathrm{Ga}$. The lowering of (002) peak intensity and the existing of (001) peak indicated the occurring structural degradation of films. This indicated that over quantity of Ga atoms in the $\mathrm{ZnO}$ crystal configuration leads to the decrease of crystalinity (Lin et al., 2010). Although, the existing of $\mathrm{Ga}$ atoms in the $\mathrm{ZnO}$ crystal could improve the crystalinity, but if the $\mathrm{Ga}$ amounts are over quantity, it leads to the defect of the crystal structure. The increase of $\mathrm{Ga}$ concentrations in the $\mathrm{ZnO}$ crystal would increase the repulsive force arising from the extra positive charges from the $\mathrm{Ga}^{3+}$, then generate the slight lattice deformation and disorder in the $\mathrm{ZnO}$ crystal as host material (Yang et al., 2009). This result is similar to the Maeng and Park (2013) work. They reported that the (002) peak intensity of $\mathrm{ZnO}$ :Ga films prepared by atomic layer deposition is significantly decreased with the increase of Ga-doped concentration.

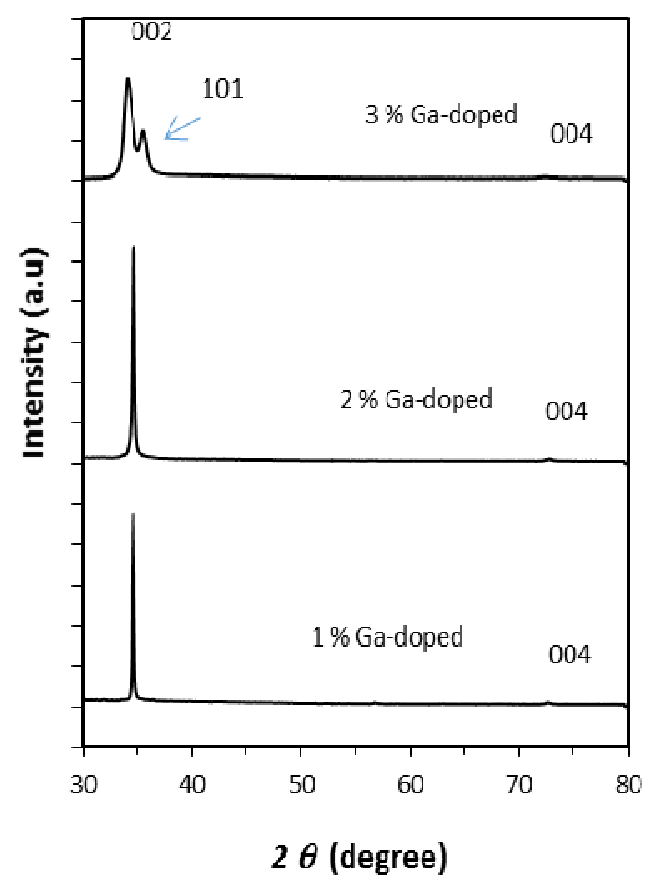

Fig. 1. X-ray diffraction patterns for $\mathrm{ZnO}$ :Ga thin films deposited at different Ga-doped concentration 
Table 1 shows structural parameters of $\mathrm{ZnO}: \mathrm{Ga}$ thin films. The crystallite size of $\mathrm{ZnO}: \mathrm{Ga}$ films have been determined from the FWHM of diffraction peak using the Scherrer formula as expressed in Equation 1.

$$
D=(0.9 \lambda) /(\beta \cos \theta)
$$

where, $D$ is the diameter of the crytallites film, $\lambda$ is the wavelength of $C u-K_{\alpha}(1.5406 \AA), \beta$ is the FWHM and $\theta$ is the Bragg angle.

From the Table 1, it can be seen that the Ga-doped has a significant contribution on the change of the crystal size of deposed films. The crystal size decreases from 42 to $12 \mathrm{~nm}$ with the increment of $\mathrm{Ga}$ concentration, while the lattice constant of $c$-axis increase from 0.519 to $0.526 \AA$. The enhancement of the $c$-axis lattice is considered due to the increment of $\mathrm{Ga}^{3+}$ ions that substitute of $\mathrm{Zn}^{2+}$, then increase the total repulsive force as previously explained.

Table 2 shows the lattice strain and stress of $\mathrm{ZnO}: \mathrm{Ga}$ thin films with different Ga-doped concentration. The lattice strain and stress were obtained from the XRD spectra analyzed. The lattice strain can be calculated by using Equation 2 (Maeng and Park, 2013).

$\varepsilon=\frac{\beta}{4 \tan \theta}$

where, $\varepsilon$ refers to lattice strain, $\beta$ is the full width half maximum (FWHM) and $\theta$ is diffraction angle. The Stress of films is given by Equation 3 .

$\sigma_{\text {film }}^{X R D}=-233 \varepsilon$

where, $\sigma_{\text {fim }}^{x R D}$ denotes the stress of thin film.

Figure 2 shows the transmittance spectra of $\mathrm{ZnO}: \mathrm{Ga}$ thin films deposited with various Ga-doped concentration. It can be seen that the transmittance of films with $1 \%$ and $2 \%$ of Ga-doped concentration achieve more than $80 \%$ in the visible region. The transmittance of films enhance with the increasing of Ga concentration. This transmittance value is similar with the transmittance spectra of the ITO thin films that deposited by Shin et al. (2009). Meanwhile, the transmittance of $\mathrm{ZnO}: \mathrm{Ga}$ film with $3 \%$ Ga-doped concentration only reach $70 \%$. This result is strongly agree with the structural properties of films i.e. the $\mathrm{ZnO}: \mathrm{Ga}(3 \%)$ film has lowest degree of crystallinity hence it is not surprising perform with the lowest transmittance. The transmittance is strongly affected by the crystallinity of the films (Lee, 2013; Li et al., 2013).

$\mathrm{ZnO}: \mathrm{Ga}$ thin films have a direct band gap, so that the absorption edge of inter band transition is given by Equation 4:

$(\alpha h v)^{2}=A\left(h v-E_{g}\right)$

where $\alpha$ refers to the absorption coefficient and $A$ denotes the constant for a direct transition. The band gap energy $\left(E_{g}\right)$ of film is obtained by plotting $\alpha^{2}$ vs. $h v$ and extrapolating the straight line of this plot to the energy (axis) as shown in Fig. 3.

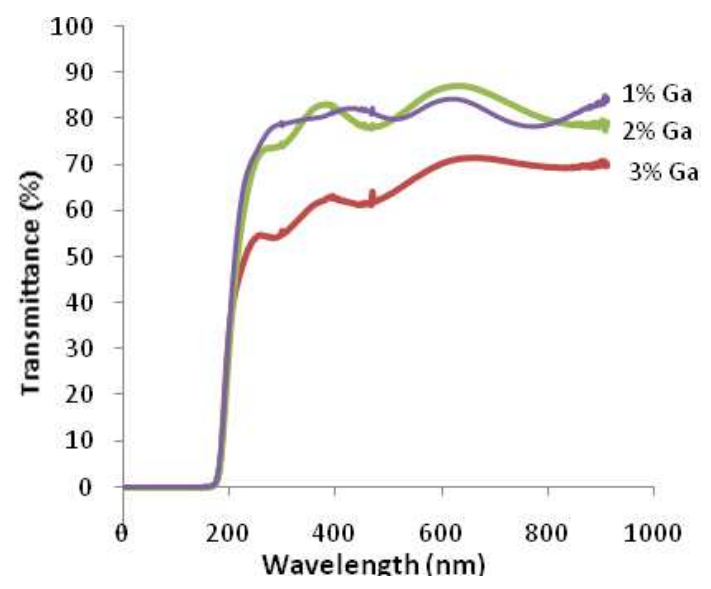

Fig. 2. The transmittance spectra of $\mathrm{ZnO}: \mathrm{Ga}$ thin films deposited at different Ga-doped concentration.

Table 1. Structural parameters of gallium doped zinc oxide thin films deposited at different Ga-doped concentration

\begin{tabular}{lllll}
\hline Ga-doped $(\%)$ & $2 \theta\left({ }^{\circ}\right)$ & Lattice constant $c(\AA)$ & Crystal size $(\mathrm{nm})$ & $\mathrm{d}$-spacing $(\AA)$ \\
\hline 1 & 34.57 & 0.519 & 42 & 2.59 \\
2 & 34.44 & 0.520 & 24 & 2.60 \\
3 & 34.05 & 0.526 & 12 & 2.63 \\
\hline
\end{tabular}

Table 2. Lattice strain and stress value of gallium doped zinc oxide thin films deposited at different Ga-doped concentration

\begin{tabular}{lll}
\hline Ga-doped (\%) & Lattice strain & Stress $(\mathrm{GPa})$ \\
\hline 1 & 0.1555 & -36.2234 \\
2 & 0.2068 & -48.2022 \\
3 & 0.5791 & -134.9198 \\
\hline
\end{tabular}




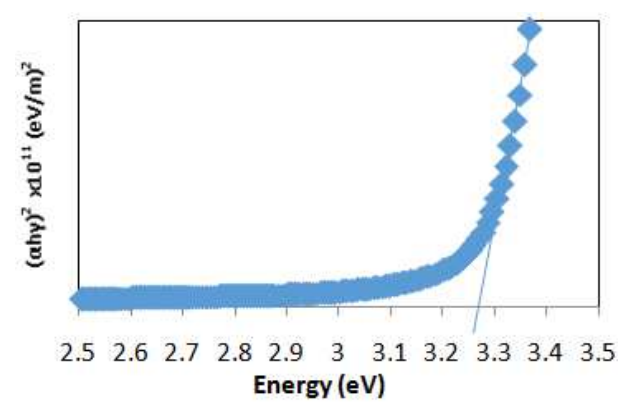

(a)

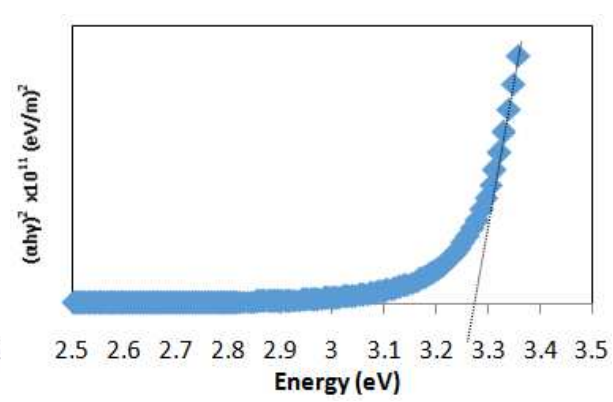

(b)

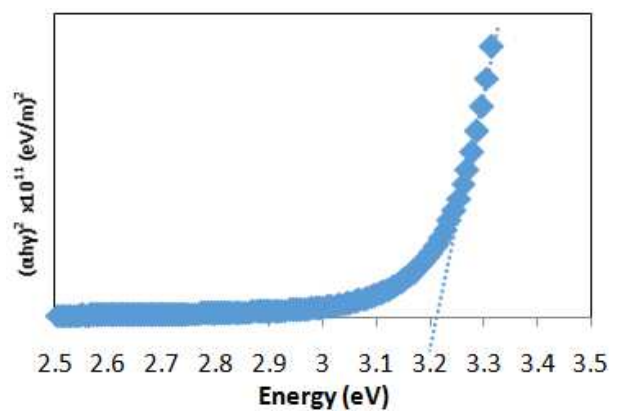

(c)

Fig. 3. The band gap $\left(E_{g}\right)$ of $\mathrm{ZnO}$ :Ga thin films with different Ga-doped concentration: (a) 1\%; (b) 2\%; and (c) $3 \%$.

Table 3 shows the band gap of $\mathrm{ZnO}$ :Ga thin films deposited at 1,2 and 3\% Ga-doped concentrations. When the Ga concentration increases from 1 to $2 \%$, the band gap, $E_{g}$ increase from 3.27 to $3.28 \mathrm{eV}$, even though the increment of the band gap is not significant, while the band gap of the $\mathrm{ZnO}: \mathrm{Ga}(3 \%)$ film is $3.21 \mathrm{eV}$. Thus, it is showed that the width of band gap affect the transmittance. Maeng and Park (2013) have deposited $\mathrm{ZnO}: \mathrm{Ga}$ thin films by atomic layer deposition. They reported that the band gap of $\mathrm{ZnO}: \mathrm{Ga}$ thin films with 1$5 \%$ Ga-doped concentrations are 3.27 to $3.60 \mathrm{eV}$. It can be seen, although we use home-made dc magnetron sputtering for deposition process, we obtained the deposited films with comparable band gab to the $\mathrm{ZnO}: \mathrm{Ga}$ films that deposited by atomic layer deposition method. This phenomenon confirms that the dc magnetron sputtering is a promising method for deposition $\mathrm{ZnO}$ :Ga films

Based on Table 3, it can be seen that the band gap of films increase from 3.21 to $3.28 \mathrm{eV}$ as the Ga concentration is decreased from 3 to $2 \%$. The widening of the optical band gap can be explained by Eq. 5 (Shin et al. 2009).

$\Delta E_{g}=\frac{\hbar^{2}}{8 m^{*}}\left(\frac{3}{\pi}\right)^{2 / 3} n_{e}^{2 / 3}$

where, $\Delta E_{g}$ denotes the shift in the doped semiconductor as compared to the un-doped $\mathrm{ZnO} ; m^{*}$ is the electron effective mass in the conduction band; $\hbar$ is the Planck'sconstant; and $n_{e}$ is the electron carrier concentration.
Table 3. Optical band gap of gallium doped zinc oxide thin films deposited at different Ga-doped concentration

\begin{tabular}{ll}
\hline Ga-doped (\%) & Band gap $(\mathrm{eV})$ \\
\hline 1 & 3.27 \\
2 & 3.28 \\
3 & 3.21 \\
\hline
\end{tabular}

Indeed, the shortening of the optical band gap is an indicator of Burstein-Moss (BM) effect. The BM effect occurs when the Fermi level enters into the conduction band (Li et al., 2013). Furthermore, the shrinking of band gap is likely due to the carrier concentration effect (Ma et al., 2007). In previous work, Shin et al., (2009) reported that the optical band gap would decrease with decreasing of carrier concentration. Maeng and Park (2013) reported that over 5\% of Ga doping, the carrier concentration of $\mathrm{ZnO}: \mathrm{Ga}$ films decrease with the increasing of doping concentrations. On the other hand, Lin et al. (2010) also reported that the carrier mobility dropped when Ga doping was laid between 3 to $10 \%$.

The correlation of optical band gaps widening with the carrier concentration has been reported by Shin et al. (2009) and Ma et al. (2007). They reported that the optical band gap increase with the increasing of carrier concentration. Thus, the carrier concentration increases as Ga-doped increases from 1 to $2 \%$, while the carrier concentration decreases as Ga-doped increases from 2 to $3 \%$. The increment of carrier concentration was considered due to the improvement of crystallinity $\quad \mathrm{Yu}$ et al., 2005). In this case, the doping of $\mathrm{Ga}$ atoms replace 
the $\mathrm{Zn}^{+}$sites in the crystal. This phenomenon causes the increase of the carrier concentration (Shin et al., 2009). On the other hand, the decreasing of carrier mobility could reduce film conductivity (Lin et al., 2010). Yu et al., (2005) have reported that $\mathrm{ZnO}: \mathrm{Ga}$ thin films doped by $3 \%$ Ga concentrations also produce film with low electrical conductivity i.e. $1.08 \times 10^{3}(\mathrm{ohm} \mathrm{cm})^{-1}$ at room temperature. Generally, however, the doping of groupIII atoms such as Al, In and Ga leads to the increment of electrical conductivity of $\mathrm{ZnO}: \mathrm{X}$ thin films (X can be Al, In or $\mathrm{Ga}$ ) compared with un-doped $\mathrm{ZnO}$ thin films (Shin et al., 2009).

The $\mathrm{ZnO}$ :Ga thin films have $\mathrm{Zn}-\mathrm{O}$ and Ga-O covalent bonds. The lengths of $\mathrm{Ga}-\mathrm{O}$ bond and $\mathrm{Zn}-\mathrm{O}$ bond are $1.92 \AA$ and $1.97 \AA$, respectively. So, $\mathrm{Ga}^{3+}$ ion has a smaller ionic radius compared to that of the $\mathrm{Zn}^{2+}$ ion. The length difference between $\mathrm{Ga}-\mathrm{O}$ bond and $\mathrm{Zn}-\mathrm{O}$ bond leads to stress of crystal and causes the stacking faults (Lee, 2013). In other words, the increase of Gadoped concentration caused the stacking faults to be shorter and denser. Therefore, the $\mathrm{Ga}$ atoms in the $\mathrm{ZnO}$ crystal could induce stress between the Ga dopant and the original lattice host material.

\section{Conclusion}

We have successfully deposited $\mathrm{ZnO}: \mathrm{Ga}$ thin films on corning glass by dc magnetron sputtering. The crystallinity of deposited films improved with the increase of $\mathrm{Ga}$ concentrations from 1 to $2 \%$, then decrease at $3 \%$ Ga concentrations. The optical transmittance of films with $1 \%$ and $2 \%$ Ga concentration reach $85 \%$ in the visible range, while at $3 \% \mathrm{Ga}$ concentration the transmittance of film only $70 \%$. We observed that the band gap of films change due to the addition of $\mathrm{Ga}$ dopant. The band gap of films are 3.27, 3.28 and $3.21 \mathrm{eV}$ for 1,2 and $3 \%$ Ga-doped concentrations, respectively. Based on the structural and optical properties of the films, $\mathrm{ZnO}: \mathrm{Ga}(2 \%)$ film is the best candidate for TCO application.

\section{Acknowledgement}

A part of this work was supported by Higher Education Collaborative Grant (Hibah Pekerti) from Generale Directorate of Higher Education of Indonesia Ministry of Education.

\section{Author's Contributions}

Putut Marwoto: The leader of the study, data analysis and writing of the manuscript.

Edy Wibowo: Data analysis and editing of the manuscript.

Dwi Suprayogi: Preparation and analysis of the sample.
Sulhadi Sulhadi: Preparation and analysis of the sample and contributed in the discussion part of the manuscript.

Didik Aryanto: Contributed in XRD analysis and the discussion part of the manuscript.

Sugianto Sugianto: Preparation of experiment apparatus, sample and data anaysis.

\section{Ethics}

This article is original. The corresponding author confirms that all of the other authors have read and approved the manuscript and no ethical issues involved.

\section{References}

Kao, J.Y., C.C. Tsao, M. Jou, W.S. Li and C.Y. Hsu, 2012. Optimization of gallium-doped $\mathrm{ZnO}$ thin films grown using Grey-Taguchi technique. J. Comput. Electron., 11: 421-430. DOI: 10.1007/s10825-0120423-X

Lee, S.Y., 2013. Controllability of structural, optical and electrical properties of $\mathrm{Ga}$ doped $\mathrm{ZnO}$ nanowires synthesized by physical vapor deposition. Trans. Electr. Electr. Mater., 14: 148-151. DOI: 10.4313/TEEM.2013.14.3.148

Li, Y., Q. Huang and X. Bi, 2013. Stress dependent properties of $\mathrm{Ga}$-doped $\mathrm{ZnO}$ thin films prepared by magnetron sputtering. J. Mater. Sci.: Mater. Electron., 24: 79-84. DOI: 10.1007/s10854-012-0862-y

Lin, K.M., Y.Y. Chen and C.Y. Chiu, 2010. Effects of growth behaviors on chemical and physical properties of sol-gel derived $\mathrm{ZnO}: \mathrm{Ga}$ films. J. Sol Gel Sci. Technol., 55: 299-305. DOI: 10.1007/s10971-010-2249-y

Ma, Q.B., Z.Z. Ye, H.P. He, L.P. Zhu and B.H. Zhao, 2007. Effects of deposition pressure on the properties of transparent conductive $\mathrm{ZnO}: \mathrm{Ga}$ films prepared by DC reactive magnetron sputtering. Mater. Sci. Semiconductor Process., 10: 167-172. DOI: 10.1016/j.mssp.2007.11.001

Maeng, W.J. and J.S. Park, 2013. Growth characteristics and film properties of gallium doped zinc oxide prepared by atomic layer deposition. J. Electroceram., 31: 338-344. DOI: 10.1007/s10832013-9848-2

Marwoto, P., Sulhadi, Sugianto, D. Aryanto, E. Wibowo and K. Wahyuningsih, 2014. Room-Temperature Deposition of $\mathrm{ZnO}$ Thin Films by using DC Magnetron Sputtering. Adv. Mater. Res. 896: 237-240. DOI: 10.4028/www.scientific.net/ AMR.896.237

Marwoto, P., Fatiatun, Sulhadi, Sugianto and D. Aryanto, 2016. Effects of argon pressure on the properties of $\mathrm{ZnO}: \mathrm{Ga}$ thin films deposited by $\mathrm{DC}$ magnetron sputtering. Proceedings of the AIP Conference, (AIPC' 16). 
Nayeef, M., W. Liaqut, S. Ali and M.A. Shafique, 2013. Synthesis of $\mathrm{ZnO} / \mathrm{Al}: \mathrm{ZnO}$ nanomaterial: Structural and band gap variation in $\mathrm{ZnO}$ nanomaterial by $\mathrm{Al}$ doping. Applied Nanosci., 3: 49-55.

DOI: $10.1007 / \mathrm{s} 13204-012-0067-y$

Sheu, J.K., K.W. Shu, M.L. Lee, C.J. Tun and G.C. Chi, 2007. Effect of thermal annealing on Ga-Doped $\mathrm{ZnO}$ films prepared by magnetron sputtering. J. Electrochem. Society, 154: H521-H524. DOI: $10.1149 / 1.2721760$

Shin, H. H., Y. H. Joung, S. J. Kang, 2009. Influence of the substrate temperature on the optical and electrical properties of Ga-doped $\mathrm{ZnO}$ thin films fabricated by pulsed laer deposition. J. Mater. Sci.: Mater. Electron., 20:704-708.

DOI: $10.1007 / \mathrm{s}$ 10854-008-9788-9
Yang, Y., J. Qi, Q. Liao, Y. Zhang and X. Yan et al., 2009. Fabrication, structural characterization and photoluminescence of Ga-doped $\mathrm{ZnO}$ nanobelts. Applied Phys. A, 94: 799-803. DOI: $10.1007 / \mathrm{s} 00339-008-4842-2$

Yu, X., J. Ma, F. Ji, Y. Wang and X. Zhang et al., 2005. Effects of sputtering power on the properties of $\mathrm{ZnO}: \mathrm{Ga}$ films deposited by r.f. magnetronsputtering at low temperature. J. Crystal Growth, 274: 474-479. DOI: 10.1016/j.jcrysgro.2004.10.037

Zhang, Z., G. Du, D. Liu, X. Wang and Y. Ma et al., 2002. Crystal growth of undoped $\mathrm{ZnO}$ films on $\mathrm{Si}$ substrates under different sputtering conditions. J. Crystal Growth, 243: 439-443.

DOI: $10.1016 / \mathrm{S} 0022-0248(02) 01569-5$ 